\title{
Developing a typology of mobile apps in higher education: A national case-study
}

Ekaterina Pechenkina

Swinburne University of Technology, Australia

\begin{abstract}
Mobile applications (apps) are used in higher education (HE) in a variety of ways, including as learning tools, study organisers, for marketing, and recruitment of new students. Purposed with easing student transition into university life, organiser apps have a capacity to assist students with various aspects of university experience, freeing up time and energy for study, while apps used as learning tools can help students solidify the content of lectures, self-test their knowledge of the subject, and collaborate with peers. Despite the proliferation of HE apps, there is still no systematic understanding of this field, with a number of important questions remaining unanswered, such as what types of apps are most commonly found in $\mathrm{HE}$, what their complex uses are, and how their affordances and functionalities are deployed by universities and students. This study addresses this gap. After analysing 177 apps affiliated with Australian universities, a typology of HE apps is proposed. Study management and navigation apps emerge as the most common types of apps offered to students, with augmented and/or virtual reality apps forming another key category. New insights are offered pertaining to the complex terrain of HE mobile apps, and problematic areas arising from this research, such as safety, student support, privacy, and equity, are discussed.
\end{abstract}

\section{Introduction}

In parallel to the growth of ownership and use of personal mobile devices (Mackay, 2014), academic interest in the field of scholarship known as mobile learning (or m-learning) is also growing. Characterised as a combination of "individualized learning with anytime and anywhere learning" and "facilitated by mobile devices", m-learning is "both formal and informal" as well as "context aware and authentic" (Gikas \& Grant, 2013; pp. 18-19). M-learning’s context-aware capacity allows learners to engage with the learning processes in a variety of locations, through a range of devices and at the time of convenience to them (Jones, Scanlon, \& Clough, 2013). Relatively low cost of telecommunications, the spread of high-speed wireless internet and the increasing quality and functionalities of mobile devices all contribute to the proliferation of m-learning practices among learners and educational institutions alike (Park, Nam, \& Cha, 2012). In particular, the increasing presence of m-learning policies in higher education (HE) institutions (Johnson, Adams Becker, Estrada, \& Freeman, 2015) can be interpreted as indicative of universities' growing interest to use mobile technologies in teaching and learning (Coffin \& Lyle, 2013; Farley et al., 2015; Roberts \& Rees, 2014).

Enabled by mobile devices, m-learning possibilities range from a short messaging service (SMS) used as “prompts for course requirements” (Herrington, Herrington, Mantei, Olney, \& Ferry, 2009; p. 2), to realtime in-class polling and exams administered via phone using the user's voice identification, to the use of smartphones as PDA (personal digital assistants) enabling learners to retrieve and engage with digitallylocated course materials, such as e-books, courseware, and recordings of lectures (Herrington et al., 2009). M-learning technologies can be classified based on the function they serve within educational contexts: Patten, Sánchez, and Tangney (2006) distinguish between administrative (e.g., timetabling), reference (e.g., accessing library or courseware resources) or interactive (e.g., feedback provision) functions of mobile technologies. Alternatively, mobile technologies can be categorised by the type of learner engagement they can foster across "collaborative, contextual, constructionist and constructivist learning environments" (Herrington et al., 2009; p. 2).

Mobile applications (or apps) are software programmes developed for use on personal wireless devices such as smartphones. Starting from their early prototypes like mobile phone based arcade games, ring tone editors, calculators and calendars, apps have since evolved and multiplied, forming a diverse field where various operating systems' in-house developed products co-exist with third-party apps, ranging in their purpose, cost and target audience (Clark, n.d.; Holzer \& Ondrus, 2011; Strain, 2015). The fragmentation of the mobile app market means app creators have to design apps for different platforms in order to reach diverse types of users (Clark, n.d.). The education field has since caught up with the growing app market. 
For instance, Google (2014) has launched its Apps for Education in 2006 while Apple's App Store featuring educational apps was launched in 2008 (Ankeny, 2016). Years on, educational apps, especially those designed for children, is a multi-million dollar market (Yelland, 2015). HE apps, however, form a field aside as they are rarely created for-profit and likely to be tailored to a particular aspect of the student experience (The GSMA Foundation, 2012).

What is known about user engagement with apps is primarily associated with app reviews and consumer complaints (Charland \& Leroux, 2011; Henze, Pielot, Poppinga, Schinke, \& Boll, 2011; Vasa, Hoon, Mouzakis, \& Noguchi, 2012) and though HE apps are normally not-for-profit, much of HE app user behaviours, for example those pertaining to the use of library services, are dictated by their habits acquired as consumers of commercial products (Miller, Vogh, \& Jennings, 2013). A primary focus of the broader m-learning field is on evaluating the effectiveness of m-learning initiatives and tools (Wu et al., 2012), with some studies also investigating student experiences and perceptions (Gikas \& Grant, 2013; Reid \& Pechenkina, 2016). HE apps, however, are rarely discussed in a holistic manner and it is timely to develop a comprehensive understanding of this field. This can be achieved by investigating how apps are used by universities to enhance various aspects of student experience, from enabling student engagement with the learning content and resources, to enabling students to find their way around campus and learning spaces and enriching students' campus-based experiences by utilising augmented and virtual reality affordances. Different from apps specifically designed as instructional tools, organiser apps, in particular, have the capacity to alleviate various stresses associated with student lifecycle.

This paper demonstrates that mobile apps are used in diverse ways by universities and proposes a typology of HE apps, contextualised within the Australian HE field. Framed as a national case study, the paper presents findings of a review of 43 Australian universities in regards to their mobile app usage: 177 apps, each associated with at least one university, are analysed. The study's focus is on apps designed for Google Android OS smartphones as android-operating smartphones are the most common in Australia (Francis, 2015).

\section{M-learning and mobile apps: Definitions, understandings and knowledge gaps}

\section{M-learning}

Facilitated by mobile technologies, m-learning can occur at un-fixed times and locations (Kukulska-Hulme, 2005), allowing learners better control over contexts and topics and enabling their decisions on "what, where, when and whether to learn” (Jones et al., 2013; p. 21). Personalised, situated, authentic, contextualised and informal types of learning processes serve as examples of what can be achieved with the affordances of mobile technologies (Kukulska-Hulme \& Traxler, 2007). Some characterised m-learning as portability, instant connectivity and context sensitivity coming together to create a unique learner experience (Cheon, Lee, Crooks, \& Song, 2012) while others (Wong \& Looi, 2011; Wong, 2012) expanded the m-learning understanding to encompass such learning dimensions as formal/informal, personalised/social, time/space, physical/digital, ubiquitous access to knowledge, multiple device usage and device switching as well as knowledge synthesis.

M-learning initiatives are likely to be driven by pragmatic goals: universities see m-learning as a way to reach out to wider student cohorts by making learning process more personalised, accessible and engaging for them (Hannon \& Al-Mahmood, 2014). M-learning initiatives are also expected to address various learning process challenges, such as low motivation, disengagement, lack of social cohesion and collaboration in groups, and even lead to improved cognition and comprehension (Dekhane \& Tsoi, 2012; Wankel \& Blessinger, 2013; Wong \& Looi, 2011). Aligned with this pragmatic 'problem'-driven trend, a significant proportion of m-learning scholarship falls under what Januszewski and Molenda (2013) categorise as studies aiming to generate evidence of a particular technology's positive impact on learning. This trend is confirmed in a recent meta-study finding that most studies analysed focus on the effectiveness of m-learning initiative or m-learning system designs, leaving such areas as "the standpoint of teachingand learning-assistance, and their critical role in ubiquitous learning” mainly un-examined (Wu et al., 2012; p. 817). 


\section{Mobile apps: Affordances and uses in HE}

Mobile apps can serve as study aids, allowing students to manipulate anatomical models of human organs (Young, 2011), take part in simulated astronomy observations (Fraknoi, 2011) and trial their knowledge of organic chemistry outside of the laboratory environment (Dekhane \& Tsoi, 2012) among other uses. Student perception of m-learning initiatives are generally positive: students believe mobile devices help them engage with content (Gikas \& Grant, 2013) and increase their confidence as learners (Heath et al., 2005). A variety of m-learning features and learning tools enabled through smartphones, including push notifications, dynamic timed quizzes, videos and engagement loops, show some successes in enriching various aspects of student experience (Oates, Pechenkina, Laurence, Eldridge, \& Hunter, 2016).

Because of the ubiquitous presence of mobile devices, students are more likely to engage with university systems and resources via apps rather than desktop computers and hence come to expect their institutions to offer such apps (Jain, n.d.). While some studies (Kinash, Brand, \& Mathew, 2012; Wong, 2012) do not record a significant student preference for accessing university services and resources via a mobile device over a desktop computer, Bowen and Pistilli (2012) find that students spend significantly more time accessing HE content and resources using available apps compared to the phone browser, this gap widening the more advanced students become in their smartphone use. An important reason for this preference can be that students appreciate an app-enabled option of a continuous access without needing to log in every time (Gikas \& Grant, 2013).

Responding to this apparent demand for apps, universities develop campus-specific apps (Bowen \& Pistilli, 2012; Cheon et al., 2012; Jain, n.d.), which are primarily non-instructional in their purpose but rather organisational, enabling students' instant access to news, announcements, event calendars, maps, course schedule, assignment grades, scheduling and so on. This apparent rise of organiser apps in HE is confirmed by another study finding that "many of the reportedly 'educational' benefits of digital technology... are... [actually] concerned with the 'logistics' of university study rather than matters related directly to 'learning' per se” (Henderson, Selwyn, Finger, \& Aston, 2015; p. 9), which means students use available technologies primarily to manage their academic lives, that is to locate and retrieve journal articles and books, submit assignments, work out course requirements and class scheduling, and access learning materials.

In regards to the HE app design, while Jain (n.d.) advocates for one-stop-shop campus apps, others (Abraham, 2014; Bratton, 2014; Designer News, 2014) argue it is better to separate apps by function because simpler, leaner, and single-focused apps ensure better user experiences as users value simplicity of the app's structure and clarity of its purpose. Various departments and units within universities, most notably libraries (Smith, Jacobs, Wilson, \& McCarthy, 2010; Wong, 2012) routinely conduct user studies to determine how student app usage can shape and improve service offerings. For instance, one such study demonstrates how the simplicity of the app's interface is perceived as advantageous by students over a conventional library website (Miller et al., 2013). Overall, students use available educational technologies, including apps, to ease and streamline their experience of being a student, which centres on the management of deadlines, retrieval of material and information and finding way between classes (Henderson et al., 2015).

\section{Apps' special features: GPS, QR, AR and VR}

As mobile devices evolve, a range of new and improved features promise new ways of enriching the student experience. For example, GPS/geolocation tools combined with augmented reality (AR) technology can help students engage with "relevant place-based information about nearby buildings or landmarks" (Cheon et al., 2012; p. 1054), while quick response (QR) code reader can be used to record student attendance (Masalha \& Hirzallah, 2014), enable outdoor education activities (Lai, Chang, Wen-Shiane, Fan, \& Wu, 2013) and deliver timely feedback (Gardiner, 2016). The AR and virtual reality (VR) features can also enable such instructional approaches as game-based, place-based and problem-based learning, participatory simulations, role playing, studio-based pedagogy, and the jigsaw method where multiple approaches are combined (Wu, Lee, Chang, \& Liang, 2013). If VR creates virtual worlds, AR brings virtual and real worlds together to 'enhance' and 'augment' reality (Wu et al., 2013). In such AR initiatives as fully immersive technologies users interact with the interface and each other using head-mounted displays, while in lightly augmented situations users interact with and manipulate virtual objects and/or peruse digitally-located information (Wu et al., 2013). While fully immersive technologies are too costly for large classes, personal mobile devices present an opportunity for educators to take advantage of some VR and AR elements. For 
example, combined with a geolocation feature, place-focused AR technology can enrich Orientation or Open Day experiences by tracking learners' location and providing them with place-specific information as they move around campus (Wu et al., 2013). AR/VR features enabled by mobile devices can also provide virtual access to remote laboratories and simulation experiences, where virtual objects such as texts, videos and pictures are used to represent concepts and engage learners (Andujar, Mejías, \& Marquez, 2011), allowing learners to annotate, manipulate and create virtual materials.

\section{Learners' relationship with technology}

Student adoption and perception of m-learning are instrumental to the success of m-learning initiatives (Park et al., 2012; Reid \& Pechenkina, 2016). Learner adoption, however, is subject to various factors, from device familiarity, technology preferences and brand loyalty (Reid \& Pechenkina, 2016), to students’ general attitude towards m-learning and their perception of its relevance to their studies and future career (Park et al., 2012). Students' age, institution, level of study and discipline also play a role in m-learning adoption (Henderson et al., 2015). In regards to apps, prior bad experiences as well as the app's negative ratings can affect its uptake by students (Khalid, Shihab, Nagappan, \& Hassan, 2015). Even students who consider themselves "technologically savvy" can struggle with technology (Gikas \& Grant, 2013; p. 23). Hence, for an m-learning initiative to succeed it needs to be designed taking into account students' motivations and needs (Park et al., 2012). In turn, learners' awareness and attitudes can be improved by offering training and support (Cheon et al., 2012). It is important to see students as a diverse group of learners, whose behaviours and perceptions influenced by a complexity of socio-demographic factors, including but not limited to contexts and quality of their access to technology, "the frequency, duration, motivations and purpose of their use, and their perceptions of its impact”, "one's home access context" and academic ability of students (Smith, Skrbis, \& Western, 2013; p. 98).

\section{The rationale for a comprehensive understanding of HE mobile apps}

Compared to the secondary education, university life demands more independence and decision-making from students and may appear unstructured to them as they are expected to not only be academically successful but to navigate the intricacies of university life, including self-management of at times competing learning and administrative tasks. Getting organised can be vital to academic success and a variety of resources and self-help guides can be found on university websites, all designed to help students manage their workload and stay on top of things. It is unsurprising then that out of 11 categories of student engagement with educational technologies, those "related to the logistics of university study" were most commonly named by students while "practices explicitly related to learning were reported less frequently" (Henderson et al., 2015; p. 314).

Their primary purpose being to help students manage various aspects of their university experience, organiser apps can assuage issues associated with student anxiety and depression, both linked with lower academic performance (Owens, Stevenson, Hadwin, \& Norgate, 2012). In particular, it is students transitioning from secondary schooling into HE who face more of these types of stressors, compared to their more experienced peers (Panda, Mandal, \& Barman, 2015). One student anxiety study (Song, Youn, \& Jung, 2014) identifies a significant negative correlation between social support and levels of stress in college students, while another (Bergin \& Pakenham, 2015) argues that competing academic demands, social isolation and study-life imbalance can lead to higher levels of depression and anxiety in university students.

By supporting students in self-management of their university lives, campus mobile apps have capacity to make student experience seamless and less stressful. Gaining a more systematic understanding of how mobile apps are used in HE would is a logical step towards conceptualising how apps and mobile technologies more widely can better serve universities and students. This paper adds to the m-learning scholarship by proposing a typology of mobile apps affiliated with Australian universities and offering new insights into how mobile app technology is leveraged by the HE industry. 


\section{Methodology: Developing a typology of higher education mobile apps}

As Google Android operating system smartphones are the most common in Australia (Francis, 2015), this study is based on publicly available app data extracted from Google Play. Conducted throughout JulyNovember 2015, a network-based systematic search of HE apps used a name of each Australian university as a keyword to identify relevant apps. As a validation mechanism, a generic term "university" as well as known abbreviations for Australian universities (e.g., UOM for University of Melbourne) were also used as keywords when gathering app data. All institutions with HE portfolios were included in this study $(N=$ 43). The study acknowledges that some universities may rely on internal servers to manage and distribute their in-house apps (Noonoo, 2014). However, due to difficulties associated with accessing this data, such apps were not included in this analysis.

All apps associated with a university (in either official or unofficial capacity, as determined by whether a university was listed as the app's developer) were entered into a database along with summaries of apprelated information, including each app's stated purpose, intended audience, and special features (e.g., AR, VR, game elements). While Google Play has its own app classification system (including broad categories of education, productivity, social, etc.), this study goes beyond generic classifications to determine an app's purpose within the HE context, and to draw conclusions based on the most and least common HE app types.

Out of 43 Australian institutions with HE portfolios, 35 have at least one Google mobile app; with 177 apps analysed in total. The number of apps per university varies from 1 to 2 , and in some instances, over 10 . The size or location of a university or whether it is a member of a group of educational institutions like Group of Eight or Innovative Research Universities does not appear to have an influence over the number or types of apps a university has. As eight institutions have no mobile apps listed to their name, this paper's findings are discussed in relation to the cohort of 35 universities which have affiliated mobile apps.

Utilising the aspects of the framework approach (Ritchie \& Lewis, 2013) to generalisable qualitative data analysis, every app's textual description is examined for common themes, repeating this thematic analysis process in iterations to allow for sub-themed to be grouped into larger themes. Drawing on Willis's (2008) classification of qualitative-data based typologies, this study seeks to develop a typology of products (apps) based on their characteristics and descriptive texts associated with them, the ultimate goal being to achieve a systematic understanding of the field. A two-tiered app typology is developed as a result of this analysis. Each identified app is analysed first for a primary type and then, if relevant, for a secondary type, where the latter is narrower than the former in its specificity of function. An app's primary type is decided based on the app's description and goals stated by its developers while the secondary type is arrived at after analysing the descriptive texts attached to the app and identifying common themes. For example, if an app is designed to help students navigate various aspects of university life, organiser/university life management is assigned as the app's primary type. If the same app also has a more targeted purpose and can serve, for instance, as a digital diary helping students manage social aspects of their university experience, the app is assigned a secondary type, student diary. As a result, the primary type tier encompasses 13 categories. Further, 152 of 177 apps have a secondary purpose and 19 types are arrived at as the second tier.

\section{Findings: Mobile app trends}

The number of apps per university averages at 5 (with 177 apps and 35 universities), and based on whether an app is university-branded (regardless of whether it is produced in-house or outsourced), 125 of 177 apps are official university apps. Another 29 apps are tagged as unofficial as those were developed by an external party (e.g., students, alumni, or commercial entities with a stake in HE) to fill a certain (perceived) gap in mobile app offerings. An example of an unofficial HE app is an app hosting a specialised networking site or facilitating an online notice board for international students. Student unions in 18 universities offer digital diary apps (all developed by PokitPal), purposed with helping students manage various social life aspects, including clubs and societies membership, shopping and finding discounts and deals. Based on the analysis of app offerings for its primary and secondary purpose, the former includes 13 types (Table 1) and the secondary includes 19 types (Table 2). 
Table 1

Mobile apps ranked by primary type

\begin{tabular}{|c|l|c|}
\hline Rank & \multicolumn{1}{|c|}{ University mobile apps by primary type } & $\begin{array}{c}\text { Number of apps: From } \\
\text { most to least common }\end{array}$ \\
\hline 1 & Organiser/University life management & 65 \\
\hline 2 & Navigator/Getting around & 23 \\
\hline 3 & Instructional & 20 \\
\hline 4 & Orientation/Open day & 15 \\
\hline 5 & Health & 13 \\
\hline 6 & Media & 10 \\
\hline 7 & International student focused & 7 \\
\hline 8 & Alumni focused & 5 \\
\hline 9 & Art and culture event/Conference & 5 \\
\hline 10 & Sports & 4 \\
\hline 11 & University promotion/Marketing & 4 \\
\hline 12 & Nature/Local area exploration & 3 \\
\hline 13 & Safety & 3 \\
\hline & Total & $\mathbf{1 7 7}$ \\
\hline
\end{tabular}

Table 2

Mobile apps ranked by secondary type

\begin{tabular}{|c|l|c|}
\hline Rank & \multicolumn{1}{|c|}{ University mobile apps by secondary type } & $\begin{array}{c}\text { Number of apps: From } \\
\text { most to least common }\end{array}$ \\
\hline 1 & One-stop-shop (multi-purpose) organiser & 19 \\
\hline 2 & Getting around: Campus & 17 \\
\hline 3 & Digital student diary & 17 \\
\hline 4 & Research project & 14 \\
\hline 5 & Getting around: Local community & 12 \\
\hline 6 & One-off event & 10 \\
\hline 7 & Unit/Discipline specific & 9 \\
\hline 8 & Media: University specific & 7 \\
\hline 9 & Learning Management System access & 4 \\
\hline 10 & Pre-departure/Orientation & 4 \\
\hline 11 & International student recruitment & 4 \\
\hline 12 & Local/University sports team & 4 \\
\hline 13 & Timetable manager & 3 \\
\hline 14 & Locating computers on campus & 3 \\
\hline 15 & Educational app for children & 2 \\
\hline 16 & Indigenous/Heritage & 2 \\
\hline 17 & Residential living & 2 \\
\hline 18 & Study Exchange & 1 \\
\hline 19 & Domestic student recruitment & $\mathbf{1 4 4}$ \\
\hline & & \\
\hline
\end{tabular}

\section{Organiser apps}

According to primary purpose, most apps in this sample are organiser apps $(N=65)$. Designed to help students coordinate various aspects of their university experience, organiser apps help students manage a variety of academic lifecycle events, from admission to enrolment, residential living, parking and getting around campus and its surrounds, to accessing LMS, library, and other services.

\section{Navigator apps}

The second most common type of apps are those assisting students with navigation of the campus grounds and surrounds $(N=23)$. GPS-equipped, navigator apps allow users to see their real-time location on campus and guide their movements between buildings. Some navigator apps are aligned with campus motion detectors' data, generating an overview of available study spaces or providing students with an estimate of 
the available computer stations in various locations on campus. Developed and maintained by local councils/municipalities for a university community, a small number $(N=5)$ of apps help students and staff navigate the areas around campus by serving as interactive maps and using a geolocation tool to enable integrated public transport schedules.

\section{Instructional apps}

Forming the third most common type of apps in the proposed typology $(N=20)$, instructional apps are those specifically designed as learning tools to either enhance student educational experience within a specific subject/unit or, to increase learners' general knowledge on a specific topic/discipline. An app offering information about care for those diagnosed with dementia is an example of the latter. Another example of an app combining the elements of an instructional tool and a research data collection method is Fireballs in the Sky which allows users to submit fireball reports to Desert Fireball Network ran by Curtin University. If enough users observe and report the same event, the reports are combined to work out the fireball's trajectory and determine its orbit before it reaches the top of earth's atmosphere. The users who reported the event then receive the details of the object's origin in the solar system. This app can be used to train science students. A website linked to the app provides a variety of educational resources, such as workbooks for science educators.

Classified as educational apps for children, three instructional apps in this sample are designed and developed by university-based academics to benefit a wider group of younger learners and their parents. These apps are commonly associated with a university-based research centre or a particular research study. For example, Discover Mworld designed by Monash University researchers combines game and visual elements to educate leaners on a variety of subjects ranging from the Arctic wildlife to the ancient world history, to physics.

Finally, unit, subject, or discipline tailored apps are designed to assist students with the use of a specific citation system or supplement the learning process by providing access to additional materials, tips, and other discipline specific knowledge in small information chunks (e.g., videos or text-based modules). For instance, linked to the medical discipline, University of New South Wales's Medicine Assessments app is designed to evaluate medical students' clinical learning and work-place based assessments. The app's stated goals are to improve the efficiency of students' in-training by allowing them to record their clinical experiences and to enable mobile access to in-training assessment documentation for supervisors. The app is linked to students' portfolio allowing them to build up the record of their professional skills and knowledge. Overall, while forming the third most common app type, instructional apps are a relatively small group compared to organiser and navigator apps, a finding in line with what is known about trends of student use of educational technologies (Henderson et al., 2015).

\section{Other app types}

The rest of the apps $(N=69)$ typified by the primary purpose include health, safety, media and student recruitment focused apps. Labelled as health, 13 apps including pollen count in the sample are designed to help manage one's health and wellbeing. As a trend, these apps are developed by university-based researchers to assist students as well as wider communities by offering free resources, videos and scenarios addressing topical health related needs. If a health app is developed as part of a university-based research project, the app is labelled research as a secondary purpose. These health/research apps are used both as a wellbeing maintenance tool and for research data collection.

Such apps as UniSafe and Lost on Campus serve as examples of cross-university safety initiatives. Originally developed by the University of Melbourne as part of its Safer Community Program, UniSafe's primarily purpose is to enable student and staff access to resources pertaining to personal safety on campus as well as more general support services. The app also works as an instant access point allowing users to request security assistance and book a chaperone to accompany them to transport (The Melbourne Newsroom, 2013). Similar apps have since been developed in two other Australian universities.

Another multi-campus initiative is Lost on Campus app. Though not developed by a university per se or a coalition of universities, Lost on Campus is nonetheless a uniquely positioned HE app initiative of strategic importance to a large group of universities. Developed by a tertiary publishing and retail organisation, Lost on Campus covers over 40,000 locations across 50 Australian campuses by mapping various campus 
spaces, including lecture theatres, tutorial rooms, computer labs and other locations. Designed specifically for new students in their first weeks on campus, the app was conceptualised and developed with input from students, who are also employed as campus-specific editors maintaining the app (Doherty, 2013; Rosenberg, 2012).

Apps labelled as media or, as a secondary type, university-specific media, enable a faculty/school or university to distribute topical newsletters or serve as student or alumni cohort-specialised media outlets. Media apps can inform subscribers of daily trends and share tips from discipline/industry insiders. Further, a small group of apps comprises those supporting recruitment of a specific student group. Such recruitment apps serve as information portals about life and study in Australia or, if targeting domestic students, provide a university-specific calculator of Australian Tertiary Admission Rank (ATAR) or its equivalents to help students identify their university options.

Art exhibits, events, and conferences management apps as well as sports apps can also be found among organiser and navigator apps. Those apps designed to assist participants of campus-based conferences or visitors of an exhibit where a university is a stakeholder, tend to be one-off apps which only stay active throughout the event's duration. On another hand, sports apps are designed to help followers of universitybased sports team stay up to date with the team's progress in competitions and hence are regularly updated.

\section{Special features: AR, VR, and games}

Most apps reviewed have designs incorporating the elements of text modules, hyperlinks, images, and embedded access to the social media platforms, YouTube, and other external platforms. In regards to special features, AR, VR, and game-based elements can be found incorporated into some apps. Only one HE app (of the instructional type) uses game elements. Its digital leaderboards are populated regularly based on participating students' online quiz scores, ranking their knowledge of lecture material. Another game element utilised is digital badging. Badges are used as a micro-credentialing tool to reward students who reach certain learning milestones. In contrast, all educational apps for children have some game elements integrated into their design.

Fifteen apps of those reviewed have an AR feature and two apps have a VR feature. Apps equipped with either AR or VR feature are event management apps developed to enhance participant experiences during Orientation Week, Open Day, and other campus-based events. Enhanced with a GPS locator and QR reader, these apps can further enhance student engagement with campus spaces, for instance by allowing students to scan QR codes placed strategically around campus to gain additional information about buildings. This information can be about campus history or linked to a specific activity, such as Orientation Week's Treasure Hunt for new students. Another type of apps equipped with AR or VR components include arts and heritage apps, such as an app assisting users in learning an Indigenous Australian language or an app enhancing visitor experience at a university-hosted art exhibit.

\section{Conclusion and future steps}

Students come to expect their universities to offer campus-specific mobile apps that enable access to a variety of services and resources. In turn, "universities have an obligation to continue to support these useful 'logistical' ... aspects” of student academic experience (Henderson et al., 2015; p. 12). In the presented typology, the majority of 177 Google Play apps analysed are in fact such logistical apps designed to help students manage various aspects of their university experience. Instructional apps (that is those specifically designed as learning tools) are in the minority. Navigator apps are likely to have AR/VR features while all educational apps for children have game elements as part of their design.

The main distinction in the non-instructional app group is between multi-purpose (one-stop-shop) and onepurpose apps, where the former is dominant. This dominance of multi-purpose apps suggests a centralised effort from universities in enabling students to manage all aspects of their academic experience through one app. As sustainable resources like staff expertise, technical support and funding are necessary to develop and maintain high quality HE apps, packaging several functions into one app means reduced maintenance costs and resources needed to keep the app up-to-date. While some (Jain, n.d.) advocate for one-stop-shop campus apps as a preferred option for students, contextualised within general app user preference trends, single-purpose apps promise a better user experience due to their simpler, clearer and leaner designs (Abraham, 2014; Bratton, 2014). In fact, in the wider app field, multi-purpose apps are 
referred to as killer apps and are seen as a recipe for a failure. In this regard, Australian HE industry's overall preference for multi-purpose apps is misaligned with what app designers suggest as best practice. At the same time, instructional apps analysed in this study primarily have one purpose and are better aligned with the general app industry.

While student engagement with HE apps is not within this study's scope, future research can focus on this important area and test various hypotheses around student preferences between multiple-purposed or solepurposed apps. In addition to analysing students' self-reported perceptions, app usage data can be utilised to predict student engagement trends (Bowen \& Pistilli, 2012). International experience with mobile apps in HE presents another important angle for future study where trends and gaps can be compared and implications for impactful practice identified. Further, expanding the data collection sites to include Apple $\mathrm{HE}$ apps will ensure an even richer analysis to further tailor the proposed typology.

The fact that most apps reviewed (125 out of 177) are official university-branded apps indicates a strong interest from Australian universities to leverage the mobile app industry's affordances to help students manage various aspects of their university experience. A very small number of unofficial apps present in the sample indicates there are not many perceived gaps in the HE mobile app offerings field, as most areas of need already being addressed by universities. As all official university apps reviewed are free of charge and only one (unofficial) app has in-app fees, it can be concluded that, as a rule, mobile app technology is used in Australian HE to benefit students, and not to generate revenue. In regards to research and development and knowledge transfer, in this study at the time of writing the sole example of a university utilising its expertise and resources to build an app for external clients comes from Griffith University’s Lab Factory. Commissioned by the City of Gold Coast, this university-based app developer created a series of map-based apps to serve the local community. These apps map the city's various public areas, including disability access points and public toilets. This is also the only example of a HE-associated app designed with an equity group in mind. While app technologies have a great potential to address various equity needs in regards to gender, disability and religion, this study does not identify any apps designed to specifically serve these groups within $\mathrm{HE}$.

While unlike their commercial counterparts (Hirsh-Pasek et al., 2015; Yelland, 2015), HE apps do not serve to generate revenue, the situation may change as evidence emerges of customisable instructional apps which demonstrate positive impact on student learning. Apps like Harvard-developed QStream are already being commercially licensed and offered to universities or individual academics for a fee. Relevant disciplinary content can then be acquired to populate the app and use it in alignment with lectures.

The questions of mobile app user privacy, equity and consent present another important area of consideration. Most apps, including those built for Google Play, do not require user's explicit permissions but rather state upfront what types of data will be collected once the app is installed on a device. This can include the lists of contacts stored on the device, Google searches, email contents, GPS-enabled location tracking, SMS messages, photographs, and so on. Of course, universities already routinely collect student clickstream data, with learning analytics being a broad term referring to the process of gathering data generated as part of students' engagement with various LMS functions. The main stated purpose of learning analytics is to make student outcomes predictions based on engagement patterns; for example, by identifying students at risk and then intervening via email or phone to offer support and resources. Such analytics data can also be shared with students to motivate them to engage and perform better. Overall, Big Data is on the rise in HE, and mobile app technology offers a major channel for data collection, though to what cause remains to be seen. Questions of student consent, data retention and storage, who has access to it and how it is used as well as how students themselves can benefit from this data need to be asked in future research. While there are studies indicating that students generally are supportive of universities collecting their usage data as long as it is used to improve their learning experience (Dahlstrom \& Bichsel, 2014), there is still an urgent need for the uniformity of approaches to understanding how mobile technology is utilised in HE. The typology presented in this paper addresses some of these questions and proposes future steps for mobile learning research.

Future developments for HE mobile apps are likely to be influenced by evolving mobile technologies and device functionalities and capabilities as well as diversifying teaching and learning needs. VR, AR, and simulation gear enabled features will continue to be used along with such functions as built-in cameras, GPS, networking capabilities, and sensors measuring touch, sound, acceleration and orientation (Dabney, Dean, \& Rogers, 2013). In particular, immersive VR enabled education will make possible a place-based 
learning in hard-to-reach or dangerous environments, such as combat zones, deep space, underwater, and so on (Burch, 2016). With the growing number of resources on how to design apps, educators keen on experimenting with mobile learning technologies will likely continue creating new app products, but it is the measurement of the apps' impact on teaching and learning that will need further attention.

\section{References}

Abraham, M. (2014, May 6). Why 'single purpose' apps are en vogue [Blog post]. Retrieved from https://marcabraham.wordpress.com/2014/06/05/why-single-purpose-apps-are-en-vogue/

Andujar, J. M., Mejías, A., \& Marquez, M. A. (2011). Augmented reality for the improvement of remote laboratories: an augmented remote laboratory. IEEE Transactions on Education, 54(3), 492-500. https://doi.org/10.1109/TE.2010.2085047

Ankeny, J. (2016). Ten billion downloads and counting: The history of Apple's App Store, and its all-time top apps. Retrieved from http://www.fiercewireless.com/special-report/ten-billion-downloads-andcounting-history-apple-s-app-store-and-its-all-time-top

Bergin, A., \& Pakenham, K. (2015). Law student stress: Relationships between academic demands, social isolation, career oressure, study/life imbalance and adjustment outcomes in law students. Psychiatry, Psychology and Law, 22(3), 388-406. https://doi.org/10.1080/13218719.2014.960026

Bowen, K., \& Pistilli, M. D. (2012). Student preferences for mobile app usage. Retrieved from http://www.educause.edu/ecar

Bratton, A. (2014). One app to rule them all - a strategy for certain doom. Retrieved from http://lextech.com/2014/06/one-app-to-rule-them-all-a-strategy-for-certain-doom/

Burch, A. (2016). The top 10 companies working on education in virtual reality and augmented reality. Retrieved from https://touchstoneresearch.com/the-top-10-companies-working-on-education-invirtual-reality-and-augmented-reality/

Charland, A., \& Leroux, B. (2011). Mobile application development: web vs. native. Communications of the ACM, 54(5), 49-53.

Cheon, J., Lee, S., Crooks, S. M., \& Song, J. (2012). An investigation of mobile learning readiness in higher education based on the theory of planned behavior. Computers \& Education, 59(3), 1054-1064. https://doi.org/10.1016/j.compedu.2012.04.015

Clark, J. (n.d.). History of mobile applications. Retrieved from http://www.uky.edu/ jclark/mas490apps/History of Mobile Apps.pdf

Coffin, T., \& Lyle, H. (2013). The use of mobile devices for academic purposes at the University of Washington: Current state and future prospects. Retrieved from http://www.washington.edu/itconnect/wp-content/uploads/2013/10/The-Use-of-Mobile-Devices-forAcademic-Purposes-at-the-University-of-Washington1.pdf

Dabney, M. H., Dean, B. C., \& Rogers, T. (2013). No sensor left behind: Enriching computing education with mobile devices. Proceeding of the 44th ACM Technical Symposium on Computer Science Education, New York, NY, 627-632. https://doi.org/10.1145/2445196.2445378

Dahlstrom, E., \& Bichsel, J. (2014). ECAR study of undergraduate students and information technology. Retrieved from http://www.educause.edu/ecar

Dekhane, S., \& Tsoi, M. Y. (2012). Designing a mobile application for conceptual understanding: Integrating learning theory with organic chemistry learning needs. International Journal of Mobile and Blended Learning, 4(3), 34-52. https://doi.org/10.4018/jmbl.2012070103

Designer News. (2014). Strategy question: "One app to rule them all" or multiple apps for different purpose? Retrieved from http://www.designernews.co/stories/31375-strategy-question-one-app-torule-them-all-or-multiple-apps-for-different-purpose

Doherty, P. (2013). Lost on campus? There's an app for that. Retrieved from http://www.smh.com.au/digital-life/smartphone-apps/lost-on-campus-theres-an-app-for-that20130810-2rogs.html

Farley, H., Murphy, A., Johnson, C., Carter, B., Lane, M., Midgley, W., ... S., Koronios, A. (2015). How do students use their mobile devices to support learning? A case study from an Australian regional university. Journal of Interactive Media in Education, 2015(1), 1-13. https://doi.org/http://doi.org/10.5334/jime.ar

Fraknoi, A. (2011). Astronomy apps for mobile devices, a first catalog. Retrieved from http://planets.utsc.utoronto.ca/ pawel/ASTB03/AER010302.pdf

Francis, H. (2015). Apple's iPhone loses top spot to Android in Australia. Retrieved from http://www.smh.com.au/digital-life/mobiles/apples-iphone-loses-top-spot-to-android-in-australia20150907-gjhc4l.html 
Gardiner, J. (2016, September). The magic of the QR code. Paper presented at the Transforming Learning Conference, Melbourne, Australia. Retrieved from http://transformconference.com/presentations/

Gikas, J., \& Grant, M. M. (2013). Mobile computing devices in higher education: Student perspectives on learning with cellphones, smartphones \& social media. The Internet and Higher Education, 19, 18-26. https://doi.org/10.1016/j.iheduc.2013.06.002

Google. (2014). Our history in depth. Retrieved from http://www.google.com.au/about/company/history/

Hannon, J., \& Al-Mahmood, R. (2014, November). The place of theory in educational technology research. Paper presented at the ASCILITE Rhetoric and Reality: Critical Perspectives on Educational Technology, Dunedin, New Zealand. Retrieved from http://www.ascilite.org/conferences/dunedin2014/files/concisepapers/322-Hannon.pdf

Heath, B. P., Herman, R. L., Lugo, G. G., Reeves, J. H., Vetter, R. J., \& Wadr, C. R. (2005). Project Numina: Enhancing student learning with handheld computers. IEEE Computer, 38(6), 46-52. https://doi.org/10.1109/MC.2005.199

Henderson, M., Selwyn, N., Finger, G., \& Aston, R. (2015). Students’ everyday engagement with digital technology in university: exploring patterns of use and 'usefulness'. Journal of Higher Education Policy and Management, 37(3), 308-319. https://doi.org/10.1080/1360080X.2015.1034424

Henze, N., Pielot, M., Poppinga, B., Schinke, T., \& Boll, S. (2011). My app is an experiment: Experience from user studies in mobile app stores. International Journal of Mobile Human Computer Interaction, 3(4), 71-91. https://doi.org/10.4018/jmhci.2011100105

Herrington, J., Herrington, A., Mantei, J., Olney, I., \& Ferry, B. (2009). Using mobile technologies to develop new ways of teaching and learning. In J. Herrington, A. Herrington, J. Mantei, I. Olney, \& B. Ferry (Eds.), New technologies, new pedagogies: Mobile learning in higher education (pp. 1-14). Wollongong, NSW: University of Wollongong.

Hirsh-Pasek, K., Zosh, J. M., Golinkoff, R. M., Gray, J. H., Robb, M. B., \& Kaufman, J. (2015). Putting education in "educational” apps: Lessons from the science of learning. Psychological Science in the Public Interest, 16(1), 3-34. https://doi.org/10.1177/1529100615569721

Holzer, A., \& Ondrus, J. (2011). Mobile application market: A developer’s perspective. Telematics and informatics, 28(1), 22-31. https://doi.org/10.1016/j.tele.2010.05.006

Jain, A. (n.d.). Mobile apps and education: Strategies for student engagement. Retrieved from http://campusconsortium.org/mobile-apps-and-education

Januszewski, A., \& Molenda, M. (Eds.). (2013). Educational technology: A definition with commentary. New York, NY: Routledge.

Johnson, L., Adams Becker, S., Estrada, V., \& Freeman, A. (2015). NMC Horizon report: Higher education edition. Retrieved from http://cdn.nmc.org/media/2015-nmc-horizon-report-HE-EN.pdf

Jones, A. C., Scanlon, E., \& Clough, G. (2013). Mobile learning: Two case studies of supporting inquiry learning in informal and semiformal settings. Computers \& Education, 61, 21-32. https://doi.org/10.1016/j.compedu.2012.08.008

Khalid, H., Shihab, E., Nagappan, M., \& Hassan, A. E. (2015). What do mobile app users complain about? IEEE Software, 32(3), 70-77. https://doi.org/10.1109/MS.2014.50

Kinash, S., Brand, J., \& Mathew, T. (2012). Challenging mobile learning discourse through research: Student perceptions of Blackboard Mobile Learn and iPads. Australasian Journal of Educational Technology, 28(4), 639-655. https://doi.org/10.1080/07380561003801590

Kukulska-Hulme, A., \& Traxler, J. (Eds.) (2005). Mobile learning: A handbook for educators and trainers. London: Routledge.

Kukulska-Hulme, A., \& Traxler, J. (2007). Designing for mobile and wireless learning. In H. Beetham, \& R. Sharpe (Eds.), Rethinking pedagogy for a digital age: Designing and delivering e-learning (pp. 180-192). London: Routledge.

Lai, H. C., Chang, C. Y., Wen-Shiane, L., Fan, Y. L., \& Wu, Y. T. (2013). The implementation of mobile learning in outdoor education: Application of QR codes. British Journal of Educational Technology, 44(2), E57-E62. https://doi.org10.1111/j.1467-8535.2012.01343.x

Mackay, M. M. (2014). Australian mobile phone lieftyle index. Retrieved from http://www.aimia.com.au/ampli2014

Masalha, F., \& Hirzallah, N. (2014). A students attendance system using QR code. International Journal of Advanced Computer Science and Applications, 5(3), 75-79. https://doi.org/10.14569/IJACSA.2014.050310

Miller, R. E., Vogh, B. S., \& Jennings, E. J. (2013). Library in an app: Testing the usability of Boopsie as a mobile library application. Journal of Web Librarianship, 7(2), 142-153. https://doi.org/10.1080/19322909.2013.779526 
Noonoo, S. (2014). Online university debuts mobile app created by in-house IT dept. Retrieved from https://campustechnology.com/articles/2014/07/21/online-university-debuts-mobile-app-created-inhouse.aspx?admgarea=news

Oates, G., Pechenkina, E., Laurence, D., Eldridge, D., \& Hunter, D. (2016, September). Push notifications, digital badges and leaderboards: Evaluating the impact of Quitch mobile application on learning. Paper presented at the Transforming Learning Conference, Melbourne, Australia. Retrieved from

http://www.researchgate.net/publication/307987458_Push_notifications_digital_badges_and_leaderbo ards_Evaluating_the_impact_of_Quitch_mobile_application_on_learning

Owens, M., Stevenson, J., Hadwin, J. A., \& Norgate, R. (2012). Anxiety and depression in academic performance: An exploration of the mediating factors of worry and working memory. School Psychology International, 33(4), 433-449. https://doi.org/10.1177/0143034311427433

Panda, S., Mandal, M., \& Barman, R. (2015). Predictors of perceived stress among university students. International Journal of Education and Management Studies, 5(4), 324-328. Retrieved from http://search.proquest.com/docview/1792354181?pq-origsite=gscholar

Park, S. Y., Nam, M. W., \& Cha, S. B. (2012). University students' behavioral intention to use mobile learning: Evaluating the technology acceptance model. British Journal of Educational Technology, 43(4), 592-605. https://doi.org/10.1111/j.1467-8535.2011.01229.x

Patten, B., Sánchez, I. A., \& Tangney, B. (2006). Designing collaborative, constructionist and contextual applications for handheld devices. Computers \& Education, 46(3), 294-308. https://doi.org/10.1016/j.compedu.2005.11.011

Reid, D., \& Pechenkina, E. (2016, October). To BYOD or not BYOD: That is the question? Investigating student preferences for mobile learning. Paper presented at the 15th World Conference on Mobile and Contexual Learning 'Mobile learning futures: Sustaining quality research and practice in mobile learning', Sydney, Australia. Retrieved from http://www.researchgate.net/publication/307926855_Bring-Your-OwnDevice_or_prescribed_mobile_technology_Investigating_student_device_preferences_for_mobile_lea rning

Ritchie, J., \& Lewis, J. (Eds.). (2013). Qualitative research practice: A guide for social science students and researchers. London: Sage Publications.

Roberts, N., \& Rees, M. (2014). Student use of mobile devices in university lectures. Australasian Journal of Educational Technology, 30(4), 415-426. https://doi.org/10.14742/ajet.589

Rosenberg, J. (2012). The smart guide to uni. Retrieved from http://www.smh.com.au/technology/technology-news/the-smart-guide-to-uni-20120227-1ty8m.html

Smith, B., Jacobs, M., Wilson, S., \& McCarthy, G. (2010). The mobile university: From the library to the campus. Reference Services Review, 38(2), 214-232. https://doi.org/10.1108/00907321011044990

Smith, J., Skrbis, Z., \& Western, M. (2013). Beneath the 'digital native'myth: Understanding young Australians’ online time use. Journal of Sociology, 49(1), 97-118. https://doi.org/10.1177/1440783311434856

Song, A.-H., Youn, H.-J., \& Jung, E.-J. (2014). Influential factors for stress and self esteem of dental hygiene students. Journal of Korean society of Dental Hygiene, 14(1), 49-57. https://doi.org/10.13065/jksdh.2014.14.01.49

Strain, M. (2015). 1983 to today: A history of mobile apps. Retrieved from http://www.theguardian.com/media-network/2015/feb/13/history-mobile-apps-future-interactivetimeline

The GSMA Foundation. (2012). Mobile education in the United States. Retrieved from http://www.gsma.com/connectedliving/wp-content/uploads/2012/03/usa110811interactive1.pdf

The Melbourne Newsroom. (2013). New UniSafe app enhances the campus experience. Retrieved from http://newsroom.melbourne.edu/news/new-unisafe-app-enhances-campus-experience

Vasa, R., Hoon, L., Mouzakis, K., \& Noguchi, A. (2012). A preliminary analysis of mobile app user reviews. Proceedings of the 24th Australian Computer-Human Interaction Conference, Melbourne, Australia, 241-244. https://doi.org/10.1145/2414536.2414577

Wankel, L., A., \& Blessinger, P. (Eds.). (2013). Increasing student engagement and retention using mobile applications: Smartphones, Skype and texting technologies. Bingley, UK: Emerald Group Publishing Limited.

Willis, J. (2008). Qualitative research methods in education and educational technology. Charlotte, NC: Information Age Publishing Inc. 
Wong, L.-H., \& Looi, C.-K. (2011). What seams do we remove in mobile-assisted seamless learning? A critical review of the literature. Computers \& Education, 57(4), 2364-2381. https://doi.org/10.1016/j.compedu.2011.06.007

Wong, L. H. (2012). A learner-centric view of mobile seamless learning. British Journal of Educational Technology, 43(1), E19-E23. https://doi.org/10.1111/j.1467-8535.2011.01245.x

Wong, S. H. R. (2012). Which platform do our users prefer: website or mobile app? Reference Services Review, 40(1), 103-115. https://doi.org/10.1108/00907321211203667

Wu, H.-K., Lee, S. W.-Y., Chang, H.-Y., \& Liang, J.-C. (2013). Current status, opportunities and challenges of augmented reality in education. Computers \& Education, 62, 41-49. https://doi.org/10.1016/j.compedu.2012.10.024

Wu, W.-H., Wu, Y.-C. J., Chen, C.-Y., Kao, H.-Y., Lin, C.-H., \& Huang, S.-H. (2012). Review of trends from mobile learning studies: A meta-analysis. Computers \& Education, 59(2), 817-827. https://doi.org/10.1016/j.compedu.2012.03.016

Yelland, N. (2015). Which apps are educational and why? It's in the eye of the beholder. Retrieved from https://theconversation.com/which-apps-are-educational-and-why-its-in-the-eye-of-the-beholder$\underline{37968}$

Young, J. (2011). Smartphones on campus: The search for 'killer'apps. Retrieved from http://www.chronicle.com/article/Smartphones-on-Campus-the/127397

Corresponding author: Ekaterina Pechenkina, epechenkina@swin.edu.au

Australasian Journal of Educational Technology (C) 2017.

Please cite as: Pechenkina, E. (2017). Developing a typology of mobile apps in higher education: A national case-study. Australasian Journal of Educational Technology, 33(4), 134-146.

https://doi.org/10.14742/ajet.3228 